\title{
PARTISIPASI MASYARAKAT TERHADAP PEMBANGUNAN INFRASTRUKTUR JALAN MELALUI PNPM-PPIP DI DESA MUNTE KECAMATAN TUMPAAN KABUPATEN MINAHASA SELATAN
}

\author{
Bryan Repi \\ Benu Olfie L. S. \\ Oktavianu Porajow \\ Jean. F. J. Timban
}

\begin{abstract}
This study aims to measure the level of public participation in the development of road infrastructure in the village plantations Munte through PNPM - PPIP . Data collection was conducted from July 2014 - February 2015. Data collection was conducted from July 2014 - February 2015. The data is in the form of primary data through a list of questions or questionnaires, and secondary data is data obtained from government Munte village, as well as scientific papers related to the study., previous literature or from the internet. The analysis technique used in this study is a descriptive analysis techniques that will be qualitative and quantitative results of this study are presented in tabular form. The results showed that the level of participation in middle category. In the planning stages of the majority of respondents are less active in participating by reason of busy work. Stages of implementation of the most respondents are not actively participating in the grounds committee perdeasaan infrastructure development program is not consistent with the results of the meeting or the decisions taken in the planning stage different from its implementation . While pemelihraan stage only 1 respondent who is not active in this stage by reason of busy work and the rest are in the active and less active, this is because the respondents have felt the results of the development so that the respondents or the public want to be involved in this stage .
\end{abstract}

Keywords : community participation, development of infrastructure and the level of participation .

Penelitian ini bertujuan untuk mengukur tingkat partisipasi masyarakat terhadap pembangunan infrastruktur jalan perkebunan yang ada di Desa Munte melalui PNPM-PPIP. Pengumpulan data dilakukan mulai dari bulan Juli 2014 - Februari 2015. Pengumpulan data dilakukan mulai dari bulan Juli 2014 Februari 2015. Data yang diperoleh adalah berupa data primer melalui daftar pertanyaan atau kuesioner, dan data sekunder yaitu data yang diperoleh dari pemerintah Desa Munte, serta karya tulis ilmiah yang berhubungan dengan penelitian., literature terdahulu maupun dari internet. Teknik analisis yang digunakan dalam penelitian ini adalah teknik analisis deskriptif kualitatif dan kuantitatif yang nantinya hasil penelitian ini disajikan dalam bentuk tabel. Hasil penelitian menunjukkan bahwa tingkat partisipasi berada pada kategori sedang. Dalam tahap perencanaan sebagian besar responden kurang aktif dalam berpartisipasi dengan alasan sibuk bekerja. Tahap pelaksanaan responden terbanyak berada pada tidak aktif berpartisipasi dengan alasan panitia program pembangunan infrastruktur perdeasaan tidak konsisten dengan hasil rapat atau keputusan yang diambil dalam tahap perencanaan berbeda dengan pelaksanaannya. Sedangkan tahap pemelihraan hanya 1 responden yang tidak aktif dalam tahap ini dengan alasan sibuk bekerja dan sisanya berada pada aktif dan kurang aktif, ini dikarenakan responden sudah merasakan hasil dari pembangunan tersebut sehingga responden atau masyarakat mau terlibat dalam tahap ini.

Kata Kunci : partisipasi masyarakat, pembangunan infrastruktur dan tingkat partisipasi 


\section{PENDAHULUAN}

\section{Latar Belakang}

Reformasi dan arus desentralisasi sejak Undang-Undang Nomor 22 tahun 1999 tentang pemerintahan daerah yang kemudian diubah dengan Undang-Undang Nomor 32 tahun 2004, paradigma pembangunan nasional telah mengalami suatu perubahan yang signifikan, dari pembangunan yang bertumpu pada negara menjadi paradigma pembangunan yang bertumpu pada masyarakat atau lebih dikenal dengan istilah pembangunan masyarakat.

Upaya untuk mengatasi permasalahan kemiskinan pada masyarakat yang cukup kompleks, pemerintah meluncurkan Program Nasional Pemberdayaan Masyarakat (PNPM) Mandiri mulai tahun 2008. Dalam kegiatan ini dirumuskan mengenai mekanisme pelibatan unsur masyarakat, mulai dari tahap perencanaan, pelaksanaan, hingga pemelihraan. Melalui proses pembangunan partisipatif, kesadaran kritis dan kemandirian masyarakat, terutama masyarakat miskin, dapat ditumbuhkembangkan sehingga masyarakat bukan lagi sebagai obyek melainkan sebagai subyek pembangunan.

Program Pembangunan Infrastruktur Pedesaan (PPIP) 2008 merupakan bagian dari PNPM, dialokasikan untuk 2.060 desa di 176 kabupaten/kota di 26 Provinsi di Indonesia. Seluruh desatersebut ialah usulan dari masyarakat dan pemerintah yang belum mendapatkan Program Kompensasi Pengurangan Subsidi Bahan Bakar Minyak. Program ini menekankan partisipasi masyarakat dalam proses kegiatannya. Program Pembangunan Infrastruktur Perdesaan 2008, dititik beratkan penanganannya pada desa tertinggal yang memiliki pelayanan infrastruktur yang rendah. Fokus utama program ini adalah :(i) pengembangan masyarakat ;(ii) pembangunan/peningkatan infrastruktur perdesaan; dan (iii) peningkatan peran stakeholder dan pemerintah daerah (Kristianto, 2013). Salah satu daerah yang mendapatkan program ini adalah Desa Munte Kecamatan Tumpaan Kabupaten Minahasa Selatan.

Pembangunan partisipasi itu menjadi penting, tidak hanya dengan sasaran pembangunan desa, atau objek pembangunan tetapi juga sebagai subyek pembangunan. Dengan demikian Pemerintah Indonesia telah meyakini bahwa partisipasi masyarakat dalam perencanaan pembangunan maupun dalam pembangunan itu sendiri merupakan salah satu syarat utama untuk keberhasilan proses pembangunan di Indonesia (Wayan, 2013). Contohnya adanya program pembangunan infrastruktur perdesaan (PPIP) sehinga infrastruktur didesa lebih baik lagi dan masyarakat juga lebih mandiri.

Jalan merupakakan sarana dan perasarana dasar yang menjadi kebutuhan penting bagi masyarakat perdesaan. Program PNPM diadakan hampir diseluruh pedesaan wilayah Sulawesi Utara dan salah satunya dilaksanakan di Desa Munte Dengan berpenduduk 1.667 jiwa dengan jumlah kepala keluarga 545, Penduduk laki-laki 884 jiwa dan perempuan berjumlah 778 jiwa. Di Desa Munte yang dilakasanakan adalah pembuatan talud, gorong-gorong dan perkerasan jalan menuju perkebunan dan jalan ini juga nantinya menjadi jalan untuk perluasan desa, merupakan program PNPMPPIP yang bersifat fisik.

Terlaksananya pembanguan jalan perkebunan ini membuat masyarakat dipermudah dalam mengangkut hasil-hasil perkebunan dan serta mempermudah pemerintah desa untuk melakukan pembangunan untuk masyarakat dalam rangka perluasan desa, dikarenakan dulunya kondisi jalan ini sangat rusak dan masyarakat tidak bisa masuk sampai kedalam perkebunan.

Dari penjelasan di atas, pembangunan infrastruktur jalan perkebunan ini sangat membantu warga. Maka menarik untuk melihat partisipasi masyarakat dalam program pembangunan infrastruktur perdesaan yang dilakukan di Desa Munte.

\section{Perumusan Masalah}

Berdasarkan latar belakang yang telah dikemukakan, maka rumusan masalah dalam penelitian ini adalah tingkat partisipasi masyarakat terhadap program pembangunan infrastruktur perdesaan (PPIP) khususnya pembangunan infrastruktur jalan perdesaan yang ada di Desa Munte?.

\section{Tujuan dan Manfaat Penelitian}


Penelitian ini bertujuan untuk mengukur tingkat partisipasi masyarakat terhadap pembangunan infrastruktur jalan perkebunan yang ada di Desa Munte melalui PNPM-PPIP.

Manfaat penelitian ini peneliti dapat menunjukan pentingnya partisipasi masyarakat dalam PNPM-PPIP dan diharapkan dapat memberikan informasi positif dan masukan pada masyarakat serta pihak-pihak yang membutuhkan khususnya kepada anggota masyarakat di Desa Munte serta menjadi bahan masukan dalam perencanaan pembangunan yang brkelanjutan.

\section{METODOLOGI PENELITIAN}

\section{Lokasi dan Waktu Penelitian}

Adapun tempat pengamatan yang dipilih yaitu Desa Munte Kecamatan Tumpaan Kabupaten Minahasa Selatan. Penentuan desa ini didasari pada pertimbangan dikarenakan faktor lokasi dan keadaan dimana peneliti merasa perlu melakukan penelitian ini. Rencana waktu yang diperlukan untuk menyelesaikan penelitian ini 7 (tujuh) bulan, dimulai dari persiapan, pengambilan data dan sampai penyusunan laporan hasil penelitian yaitu pada bulan Juli, Agustus sampai Februari 2015.

\section{Metode Pengumpulan Data}

Metode pengumpulan data dalam penelitian ini adalah survei. Pengambilan data berupa data primer melalui daftar pertanyaan atau kuesioner, dan data sekunder yaitu data yang diperoleh dari pemerintah Desa Munte, serta karya tulis ilmiah yang berhubungan dengan penelitian.

\section{Metode Pengambilan Sampel}

Pengambilan sampel mengunakan metode purposive sampling, jumlah responden sebanyak 15 orang yang merupakan masyarakat dan oarng-orang yang terlibat langsung dalam pembangunan jalan perkebunan dan yang menjadi sampelnya adalah kepala keluarga.

\section{Konsep Pengukuran Variabel}

Variabel yang diukur dalam penelitian ini adalah:

1. Karakteristik dari masyarakat:
- Umur responden

$>\leq 40$ Tahun, 41-50 Tahun dan $>50$ Tahun

- Pekerjaan responden

$$
>\text { Petani dan PNS }
$$

- Tingkat pendidikan

$$
>\mathrm{SD}, \mathrm{SMP}, \mathrm{SMA} \text { dan } \mathrm{PT}
$$

2. Partisipasi responden dalam Program Pembangunan Infrastruktur Perdesaan yang dilaksanakan dari :

A. Tahap perencanaan

1) $\operatorname{Aktif}(3)=$ Responden memberikan partisipasi dalam bentuk:

- Partisipasi kehadiran dimana responden hadir dalam rapat sebanyak 3 dari 3 kali pertemuan.

- Keaktifan dalam rapat dimana responden selalu memberikan saran/usulan disetiap rapat yang diikuti.

2) Kurang $\operatorname{Aktif}(2)=$ Responden memberikan partisipasi dalam bentu:

- Partisipasi kehadiran dimana responden hadir dalam rapat sebanyak 2-1 kali dari 3 kali pertemuan.

- Keaktifan dalam rapat dimana responden selalu memberikan saran/usulan disetiap rapat yang diikuti.

3) Tidak Aktif(1) = Responden tidak memberikan partisipasi dalam bentuk apapun.

B. Tahap Pelaksanaan

1) $\operatorname{Aktif}(3)=$ Responden memberikan partisipasi dalam bentu:

- Partisipasi dalam bentuk tenaga, dimana responden mengambil bagian dalam setiap pelaksanaan kegiatan.

- Partisipasi berupa benda, dimana responden membawa peralatan kerja saat pelaksanaan kegiatan.

2) Kurang Aktif(2) = Responden memberikan partisipasi dalam bentu:

- Partisipasi dalam bentuk tenaga, dimana responden hanya berapakali mengambil bagian dalam pelaksanaan kegiatan atau tidak sepenuhnya 
mengambiul bagian dalam pelaksanaan kegiatan.

- Partisipasi berupa benda, dimana responden membawa peralatan kerja saat pelaksanaan kegiatan.

3) Tidak Aktif(1) = Responden tidak memberikan partisipasi dalam bentuk apapun.

C. Tahap Pemeliharaan

1) Aktif(3) = Responden memberikan partisipasi dalam bentu:

- Partisipasi tenaga dimana responden selalu mengambil bagian dalam mengikuti setiap kegiatan kerja bakti.

- Partisipasi uang dimana responden memberikan uang untuk tahap oprasi/pemelihraan.

2) Kurang Aktif (2) = Responden memberikan partisipasi dalam bentu:

- Partisipasi tenaga dimana responden tidak selalu mengikuti kerja bakti.

- Partisipasi uang dimana responden memberikan uang untuk tahap oprasi/pemelihraan.

3) Tidak Aktif (1) = Responden tidak memberikan partisipasi dalam bentuk apapun.

Jumlah skor yang berada pada aktif $=3$, kurang aktif $=2$ dan tidak aktif $=1$. Tingkat partisipasi masyarakat ditentukan berdasarkan total skor partisipasi dari stiap masing-masing tingkatan yaitu tinggi, sedang dan rendah.

\section{Teknik Analisis Data}

Teknik analisis yang digunakan dalam penelitian ini adalah teknik analisis deskriptif kualitatif dan kuantitatif yang nantinya hasil penelitian ini disajikan dalam bentuk tabel.

\section{HASIL DAN PEMBAHASAN}

\section{Deskripsi Daerah Penelitian}

\section{Letak Geografis, Luas Wilayah, Batas Administrasi dan Klimatologi}

Dalam penelitian ini, wilayah yang termasuk adalah wilayah administrasi Desa Munte,
Kecamatan Tumpaan yang merupakan bagian dari Kabupaten Minahasa Selatan.Luas keseluruhan desa Munte adalah 12.557,5 Ha. Dengan batas wilayah :

$>$ Sebelah Timur : Desa Tangkunei,

$>$ Sebelah Barat : Kawasan Hutan Lindung

$>$ Sebelah Selatan : Desa Lelema

$>$ Sebelah Utara : Desa Senduk

Curah hujan 600 Mm, Jumlah Bulan Hujan

6-8 bulan, Kelembapan $128 \mathrm{Mm}$, Suhu rata-rata harian $32^{\circ} \mathrm{C}$

\section{Jumlah Penduduk Desa Munte}

Berdasarkan data Pemetaan Swadaya (PS), jumlah penduduk Desa Munte sebanyak 1.667 jiwa dengan jumlah kepala keluarga (KK) $545 \mathrm{KK}$ yang menempati 10 jaga. Tabel 1 menunjukkan bahwa jumlah penduduk laki-laki lebih besar dari jumlah penduduk perempuan. Jumlah penduduk laki-laki yang lebih banyak berada di jaga IV sebanyak 116 orang dan penduduk sedikit di jaga $\mathrm{X}$ dengan jumlah 53 orang. sedangkan jumlah penduduk perempuan paling banyak di jaga IV sebanyak 220 orang dan paling redah di jaga $\mathrm{V}$ dengan jumlah 53 orang. Sehinga total jumlah penduduk terbesar berada pada jaga IV sebanyak 220 orang atau $13.2 \%$ sedangkan jumlah penduduk paling sedikit berada pada jaga $X$ dengan jumlah 110 orang atau $6.6 \%$. Persentase jumlah KK yang paling besar ada di jaga IV sebesar $68 \mathrm{KK}$ atau $12.4 \%$ dan yang sedikit di jaga $\mathrm{V}$ dengan jumlah $39 \mathrm{KK}$ atau $7.1 \%$.

\section{Karakteristik Responden Umur Responden}

Perbedaan usia atau umur juga mempengaruhi tingkat partisipasi masyarakat. Dalam masyarakat terdapat pembedaan kedudukan dan derajat atas dasar senioritas, sehingga akan memunculkan golongan tua dan golongan muda. Produktivitas seseorang dapat di pengaruhi oleh umur, biasanya umur yang lebih mudah tingkat produktivitas tinggi sedangakan umur $>50$ tahun tingkat produktivitasnya lebih rendah. Hasil penelitian di Desa Munte, umur responder dapat dilihat pada Table 2. Tabel 2 menunjukan bahwa persentase terbesar adalah umur $\leq 40$ tahun yaitu sebanyak 6 orang atau 40 persen sedangkan presentase terkecil adalah berumur 41-50 yaitu 4 orang atau 26.7 
persen. Tabel ini juga menunjukan bahwa jumlah responden di tingkat umur tidak jauh berbeda

Tabel 1. Jumlah Penduduk di Desa Munte dimana umur $\leq 40$ ada 6 orang, umur $41-50$ ada 4 orang dan $>50$ berjumlah 5 orang.

\begin{tabular}{|c|c|c|c|c|c|}
\hline \multirow{2}{*}{ No } & \multirow{2}{*}{ Jaga } & \multicolumn{3}{|c|}{ JUMLAH PENDUDUK } & \multirow{2}{*}{ Jumlah KK } \\
\hline & & $\mathbf{L}$ & $\mathbf{P}$ & TOTAL / (\%) & \\
\hline 1 & I & 86 & 89 & $175 / 10.5$ & $55 / 10.1$ \\
\hline 2 & II & 85 & 72 & $157 / 9.4$ & $55 / 10.1$ \\
\hline 3 & III & 96 & 91 & $187 / 11.2$ & $65 / 12$ \\
\hline 4 & IV & 116 & 110 & $220 / 13.2$ & $68 / 12.4$ \\
\hline 5 & $\mathbf{V}$ & 62 & 53 & $115 / 6.7$ & $39 / 7.1$ \\
\hline 6 & VI & 77 & 66 & $143 / 8.6$ & $47 / 8.6$ \\
\hline 7 & VII & 95 & 82 & $177 / 10.6$ & $64 / 11.7$ \\
\hline 8 & VII & 94 & 89 & $183 / 11$ & $62 / 11.4$ \\
\hline 9 & IX & 66 & 69 & $135 / 8$ & $45 / 8.2$ \\
\hline 10 & $\mathbf{X}$ & 53 & 57 & $110 / 6.6$ & $43 / 7.9$ \\
\hline & & 889 & 778 & $1667 / 100$ & $545 / 100$ \\
\hline
\end{tabular}

Sumber data: data sekunder

\section{Karakteristik Responden $\underline{\text { Umur Responden }}$}

Perbedaan usia atau umur juga mempengaruhi tingkat partisipasi masyarakat. Dalam masyarakat terdapat pembedaan kedudukan dan derajat atas dasar senioritas, sehingga akan memunculkan golongan tua dan golongan muda. Produktivitas seseorang dapat di pengaruhi oleh umur, biasanya umur yang lebih mudah tingkat produktivitas tinggi sedangakan umur $>50$ tahun tingkat produktivitasnya lebih rendah. Hasil penelitian di Desa Munte, umur responder dapat dilihat pada Table 2.

\section{Tabel 2. Jumlah Responden menurut Umur}

\begin{tabular}{cccc}
\hline No & $\begin{array}{c}\text { Umur } \\
\text { (tahun) }\end{array}$ & $\begin{array}{c}\text { Jumlah } \\
\text { Responden } \\
\text { (orang) }\end{array}$ & $\begin{array}{c}\text { Persentase } \\
(\%)\end{array}$ \\
\hline & $\leq 40$ & 6 & 40 \\
1 & $41-50$ & 4 & 26.7 \\
3 & $>50$ & 5 & 33.3 \\
\hline \multicolumn{2}{c}{ Jumlah } & 15 & 100 \\
\hline
\end{tabular}

Sumber Data: Diolah dari Data Primer, 2014
Tabel 2 menunjukan bahwa persentase terbesar adalah umur $\leq 40$ tahun yaitu sebanyak 6 orang atau 40 persen sedangkan presentase terkecil adalah berumur 41-50 yaitu 4 orang atau 26.7 persen. Tabel ini juga menunjukan bahwa jumlah responden di tingkat umur tidak jauh berbeda dimana umur $\leq 40$ ada 6 orang, umur 41-50 ada 4 orang dan $>50$ berjumlah 5 orang.

\section{Pekerjaan}

Pekerjaan merupakan partisipasi masyarakat dimana lebih tinggi pekerjaan atau jabatan yang di pegang responden maka tingkat partisipasi masyarakat akan lebih rendah dimana responden hanya memberikan partisipasi dalam bentuk uang atau materi.

\begin{tabular}{lccc}
$\begin{array}{l}\text { Tabel 3. Jumlah } \\
\text { Pekerjaan }\end{array}$ & Responden & menurut \\
\hline No $\quad$ Pekerjaan & $\begin{array}{c}\text { Jumlah } \\
\text { Responden } \\
\text { (orang) }\end{array}$ & $\begin{array}{c}\text { Persentase } \\
(\%)\end{array}$ \\
\hline
\end{tabular}




\begin{tabular}{|c|c|c|c|}
\hline 1 & Petani & 14 & 93.3 \\
\hline 2 & PNS & 1 & 6.7 \\
\hline & Jumlah & 15 & 100 \\
\hline
\end{tabular}

Sumber Data: Diolah dari Data Primer, 2014

Petani merupakan yang mayoritas responden dimana Tabel 3 menunjukan ada 14 orang atau 93.3 persen dan hanya 1 orang yang memiliki pekerjaan berbeda yaitu PNS.

\section{Tingkat Pendidikan}

Salah satu faktor yang mempengaruhi tingkat pengetahuan adalah tingkat pendidikan. Semakin tinggi latar belakang pendidikan seseorang, tentunya mempunyai pengetahuan yang luas tentang pembangunan dan bentuk serta tata cara partisipasi yang dapat diberikan. Faktor pendidikan dianggap penting karena dengan pendidikan yang diperoleh, seseorang lebih mudah berkomunikasi dengan orang luar, dan cepat tanggap terhadap inovasi. Pendidikan juga merupakan kebutuhan pokok bagi setiap masyarakat dalam peningkatkan sumber daya manusia. Berdasarkan hasil penelitian, tingkat pendidikan responden bervariasi dan dapat dilihat pada Tabel 4.

\section{Tabel 4. Jumlah Responden menurut} Pendidikan

\begin{tabular}{cccc}
\hline No & $\begin{array}{c}\text { Tingkat } \\
\text { Pendidikan }\end{array}$ & $\begin{array}{c}\text { Jumlah } \\
\text { Responden } \\
\text { (orang) }\end{array}$ & $\begin{array}{c}\text { Persentase } \\
(\%)\end{array}$ \\
\hline 1 & SD & 5 & 33.3 \\
2 & SMP & 5 & 33.3 \\
3 & SMA & 4 & 26.7 \\
4 & PT & 1 & 6.7 \\
\hline & Jumlah & 15 & 100 \\
\hline
\end{tabular}

Sumber Data: Diolah dari Data Primer, 2014

Dari Tabel 4 menunjukan bahwa tingkat pendidikan responden masih tergolong rendah dimana sebagian besar pada tingkat pendidikan SD dan SMP masing-masing berjumlah 5, sedangkan sisannya SMA berjumlah 4 dan PT hannya 1 orang.

\section{Partisipasi Responden dalam Program Pem- bangunan Infrastruktur Perdesaan.}

\section{Tahap Perencanaan}

Dalam tahap perencanaan pembangunan dibutuhkan keikutsertaan masyarakat melalui tahapan - tahapan sebagaimana yang termuat dalam program yaitu dimulai dari pengalian gagasan pada tingkat jaga dan berlanjut pada musywarah desa (Musdes) kegiatan musyawarah pembangunan ini dilaksanakan untuk menyerap aspirasi masyarakatdesa tentang kegiatan yang akan dilakukan pada program tersebut, kemudian diikutsertakan dalam musyawarah rencana pembangunan (Musrembang) tingkat kecamatan. Bentuk partisipasi masyarakat yang diberikan dalam tahap perencanaan adalah kehadiran dalam rapat serta keaktifan dalam member saran/usulan. Untuk melihat bentuk partisipasi yang diberikan masyarakat dapat dilihat pada Tabel 5.

Tabel 5. Bentuk Partisipasi Dari Masyarakat

\begin{tabular}{cccc}
\hline No & $\begin{array}{c}\text { Bentuk } \\
\text { Partisipasi }\end{array}$ & $\begin{array}{c}\text { Jumlah } \\
\text { Responden } \\
\text { (orang) }\end{array}$ & $\begin{array}{c}\text { Persentase } \\
(\%)\end{array}$ \\
\hline 1 & $\begin{array}{c}\text { Kehadiran } \\
\text { dan memberi } \\
\text { Saran/Usul } \\
\text { Kehadiran } \\
\text { Tidak }\end{array}$ & 6 & 40 \\
3 & $\begin{array}{c}\text { memberikan } \\
\text { partisipasi }\end{array}$ & 7 & 13.3 \\
\hline & Jumlah & 15 & 100 \\
\hline
\end{tabular}

Sumber Data: Diolah dari Data Primer, 2014

Dari Tabel 5 menunjukkan 7 orang atau $46.7 \%$ yang tidak memberikan partisipasi sedangakn 6 orang atau 40\% memberikan 
partisipasi melalui kehadiran serta memberikan saran/usul dan sisanya 2 orang atau $13.3 \%$ hanya menghadiri pertemuan.

Hasil penelitian di Desa Munte bahwa keikutsertaan masyarakat dalam perencanaan dapat dilihat dalam Tabel 6.

\begin{tabular}{|c|c|c|c|}
\hline Tabe & $\begin{array}{r}\text { 6. Jumlah } \\
\text { Partisipasi } \\
\text { PPIP Pada }\end{array}$ & $\begin{array}{c}\text { Responder } \\
\text { Masyaraka } \\
\text { Tahap Pereı }\end{array}$ & $\begin{array}{l}\text { menurut } \\
\text { Terhadap } \\
\text { canaan } \\
\end{array}$ \\
\hline No & $\begin{array}{l}\text { Partisipasi } \\
\text { Masyarakat }\end{array}$ & $\begin{array}{c}\text { Jumlah } \\
\text { Responden } \\
\text { (orang) }\end{array}$ & $\begin{array}{c}\text { Persentase } \\
(\%)\end{array}$ \\
\hline 1 & Aktif & 2 & 13.3 \\
\hline 2 & Kurang Aktif & 6 & 40 \\
\hline 3 & Tidak Aktif & 7 & 46.7 \\
\hline & Jumlah & 15 & 100 \\
\hline
\end{tabular}

Sumber Data: Diolah dari Data Primer, 2014

Dari hasil kuisioner yang diberikan kepada responden berkaitan dengan berpartisipasi pada tahap perencanaan pembangunan prasarana lingkungan melalui Program Pembangunan Infrastruktur Perdesaan (PPIP), jumlah terbanyak 7 orang atau $46.7 \%$ responden tidak ikut atau tidak aktif berpartisipasi seperti terlihat pada Tabel 6, pada kegiatan perencanaan pertemuan desa merupakan bentuk partisipasi masyarakat melalui kehadiran dalam pertemuan dan memberikan ide atau pemikiran tentang infrastruktur desa yang akan dibangun. Dengan banyaknya yang tidak aktif dalam tahap ini berbagai alasan yang diberikan sebagian adalah sibuk bekerja dan tidak smpat hadir dalam pertemuan dikarenakan lelah sepulang kerja.

\section{Umur dan partisipasi masyarakat pada tahap perencanaan}

Berikut ini akan disajikan dalam bentuk Tabel 7 Umur responden dengan partisipasi masyarakat terhadap PPIP pada tahap perencanaan.

\section{Tabel 7. Jumlah Responden menurut Umur dalam Partisipasi Masyarakat terhadap Program Pembangunan Infrastruktur Perdesaan}

\begin{tabular}{|c|c|c|c|c|c|}
\hline \multirow{3}{*}{ No } & \multirow{3}{*}{ Umur } & \multirow{2}{*}{\multicolumn{3}{|c|}{$\begin{array}{c}\text { Tahap Perencanaan } \\
\text { Partisipasi Masyarakat }\end{array}$}} & \multirow{3}{*}{$\begin{array}{c}\text { Total / } \\
\text { Persentase } \\
(\%)\end{array}$} \\
\hline & & & & & \\
\hline & & Aktif & $\begin{array}{c}\text { Kurang } \\
\text { Aktif }\end{array}$ & $\begin{array}{l}\text { Tidak } \\
\text { Aktif }\end{array}$ & \\
\hline 1 & $\leq 40$ & 1 & 3 & 2 & $6 / 40$ \\
\hline 2 & $\overline{41-50}$ & - & 1 & 3 & $4 / 26.7$ \\
\hline 3 & $>50$ & 1 & 2 & 2 & $5 / 33.3$ \\
\hline \multicolumn{2}{|c|}{ Jumlah } & 2 & 6 & 7 & $15 / 100$ \\
\hline
\end{tabular}

Sumber Data: Diolah dari Data Primer, 2014

Tabel 7 menunjukan partisipasi masyarakat terhadap PPIP pada tahap perencanaan berdasarkan kategori umur. Pada umur $\leq 40$ tahun yang aktif 1 responden, kurang aktif 3 responden dan tidak aktif berjumlah 2 responden dari jumlah responden berjumlah 6 orang atau 40\%. Pada umur 41-50 yang aktif tidak ada responden, kurang aktif 1 responden dan tidak aktif berjumlah 3 responden dari jumlah responden sebanyak 4 orang atau $26.7 \%$ dan umur $>50$ tahun yang aktif berjumlah 1 reponden, kurang aktif 2 responden dan tidak aktif 2 responden dari jumlah responden sebanyak 5 orang atau $33.3 \%$. dimana jumlah tidak aktif lebih banyak dibandikan dengan aktif dan kurang aktif berjumlah 7 responden.

\section{Pekerjaan dan partisipasi masyarakat pada tahap perencanaan}

Berikut ini Tabel 8 menunjukan bentuk partisipasi reponden terhadap Program Pembangunan Infrastruktur Perdeaan dari pekerjaan pada tahap perencanaan. 
ASE - Volume 11 Nomor 1, Januari 2015: 38 - 50

$=$ 


\begin{tabular}{|c|c|c|c|c|c|}
\hline \multirow[t]{3}{*}{ Tabe } & \multicolumn{2}{|c|}{$\begin{array}{l}\text { 8. Jumlah } \\
\text { Partisipasi }\end{array}$} & \multicolumn{2}{|c|}{$\begin{array}{l}\text { Responden } \\
\text { Masyarakat }\end{array}$} & \multirow{3}{*}{$\begin{array}{l}\text { Menurut } \\
\text { Terhadap } \\
\text { encanaan }\end{array}$} \\
\hline & PPII & Pada & Taha & & \\
\hline & Berd & arkan & Kateg & ri F & \\
\hline \multirow{3}{*}{ No } & \multirow{3}{*}{ Pekerjaan } & \multicolumn{3}{|c|}{$\begin{array}{c}\text { Tahap Perencanaan } \\
\text { Partisipasi Masyarakat }\end{array}$} & \multirow{3}{*}{$\begin{array}{c}\text { Total / } \\
\text { Persentase } \\
(\%)\end{array}$} \\
\hline & & \multirow{2}{*}{ Aktif } & Kurang & $\frac{\text { akat }}{\text { Tidak }}$ & \\
\hline & & & Aktif & Aktif & \\
\hline 1 & Petani & 2 & 5 & 7 & $14 / 93,3$ \\
\hline \multirow[t]{2}{*}{2} & PNS & . & 1 & - & $1 / 6.7$ \\
\hline & umlah & 2 & 6 & 7 & $15 / 100$ \\
\hline
\end{tabular}

Sumber Data: Diolah dari Data Primer, 2014

Dari hasil penelitian paling besar pekerjaan responden adalah petani dimana ada 14 orang dan hanyal orang yang pekerjaannya sebagai PNS dan dari seluruh responden ada 7 orang yang tidak aktif dalam tahap perencanaan.

\section{Pendidikan dan partisipasi masyarakat pada tahap perencanaan}

Tabel 9 menunjukan partisipasi masyarakat terhadap program pembangunan infrastruktur perdesaan menurut kategori pendidikan dalam tahap perencanaan.

\section{Tabel 9. Pendidikan Responden Dengan Partisipasi Masyarakat Pada Pembangunan Infrastruktur Perdesaan}

\begin{tabular}{|c|c|c|c|c|c|}
\hline \multirow{3}{*}{ No } & \multirow{3}{*}{ Pendidikan } & \multirow{2}{*}{\multicolumn{3}{|c|}{$\begin{array}{c}\text { Tahap Perencanaan } \\
\text { Partisipasi Masyarakat }\end{array}$}} & \multirow{3}{*}{$\begin{array}{c}\text { Total / } \\
\text { Persentase } \\
\quad(\%)\end{array}$} \\
\hline & & & & & \\
\hline & & Aktif & $\begin{array}{c}\text { Kurang } \\
\text { Aktif }\end{array}$ & $\begin{array}{l}\text { Tidak } \\
\text { Aktif }\end{array}$ & \\
\hline 1 & SD & - & 2 & 3 & $5 / 33$ \\
\hline 2 & SMP & 1 & 1 & 3 & $5 / 33.3$ \\
\hline 3 & SMA & 1 & 2 & 1 & $4 / 26.7$ \\
\hline 4 & $\mathrm{PT}$ & - & 1 & - & $1 / 6.7$ \\
\hline & Jumlah & 2 & 6 & 7 & $15 / 100$ \\
\hline
\end{tabular}

Sumber Data: Diolah dari Data Primer, 2014

Tabel 9 di atas menunjukan tingkat pendidikan juga berpengaruh dalam perencanaan dimana sebagian besar yang berpendidikan SD dan SMP tidak aktif dalam perencanaan, dimana dari masing-masing 5 responden pada tingkat SD dan SMP 3 orang diantaranya tidak aktif. Tingkat SMA dari 4 responden 1 ornag aktif, 2 orng tidak aktif dan 1 orang lagi tidak aktif. Sedangkan tingkat PT yang hanya 1 responden kurang aktif dalam tahap perencanaan.

Ada pun beragam alasan responden, sehingga mereka tidak ikut berpartisipasi, yang pada intinya adalah karena kesibukan bekerja dimana mayoritas responden adalah petani dalam perencanaan pembangunan prasarana lingkungan melalui Program Pembangunan Infrastruktur Perdesaan (PPIP).

\section{Tahap Pelaksanaan}

Tahap pelaksanaan merupakan tahap dimana fisik pembangunan infratruktur ini dilakukan dari suatu program ini, dimana dibutuhkan kerja sama masyarakat dalam bentuk partisipasi, dalam pelaksanaan pembuatan jalan ini partisipasi masyarakat diwujudkan dalam bentuk tenaga serta peralatan atau benda

\section{Tabel 10. Bentuk Partisipasi Dari} Masyarakat

\begin{tabular}{|c|c|c|c|}
\hline No & $\begin{array}{c}\text { Bentuk } \\
\text { Partisipasi }\end{array}$ & $\begin{array}{c}\text { Jumlah } \\
\text { Responden } \\
\text { (orang) }\end{array}$ & $\begin{array}{c}\text { Persentase } \\
(\%)\end{array}$ \\
\hline 1 & \multirow{3}{*}{$\begin{array}{c}\text { Tenaga dan } \\
\text { Peralatan } \\
\text { Tenaga } \\
\text { Tidak } \\
\text { berpartisipasi }\end{array}$} & 2 & 13.3 \\
\hline 2 & & 4 & 26.7 \\
\hline 3 & & 9 & 60 \\
\hline & Jumlah & 15 & 100 \\
\hline
\end{tabular}

Sumber Data: Diolah dari Data Primer, 2014

Dari hasil penelitian ini paling besar masyarakat tidak berpartisipasi dimana 9 orang atau $60 \%$, berbagai alasan yang diberikan karena tidak bisa mengikuti pelaksanaan, diikuti dengan partisipasi dalam bentuk tenaga ada 4 orang sedangkan partisipasi dalam bentuk tenaga dan peralatan hanya 2 orang atau $13.3 \%$. Partisipasi masyarakat pada tahap pelaksanaan juga dapat diukur dari wujud partisipasi masyarakat.

Untuk mengetahui berapa besar partisipasi responden dalam program ini, dapat dilihat pada Tabel 11. 
Tabel 11. Jumlah Responden menurut Partisipasi Masyarakat Terhadap PPIP Pada Tahap Pelaksanaan

\begin{tabular}{lccc}
\hline No & Partisipasi & $\begin{array}{c}\text { Jumlah } \\
\text { Responden } \\
\text { (orng) }\end{array}$ & $\begin{array}{c}\text { Persentase } \\
(\%)\end{array}$ \\
\hline & & & \\
1 & Aktif & 4 & 26.7 \\
2 & Kurang Aktif & 2 & 13.3 \\
3 & Tidak Aktif & 9 & 60 \\
& & & 100 \\
\hline
\end{tabular}

Sumber Data: Diolah dari Data Primer, 2014

Dari hasil wawancara terlihat partisipasi masyarakat di Desa Munte, partisipasi yang terbesar pada pelaksanaan pembangunan infrastruktur desa adalah ketidak aktifan masyarakat untuk berpartisipasi yang mencapai $60 \%$, atau 9 orang kemudian diikuti oleh 53,3\% atau 8 orang, serta dana $33,3 \%$ atau 5 orang.

Berdasarkan realisasi sumber pembiayaan kegiatan, total biaya yang dikeluarkan pada PNPM-PPIP di Desa Munte adalah Rp. 251.800.000, bantuan dana PNPM Mandiri Rp. 250.000.000 dan sisanya Rp. 1.800 .000 merupakan partisipasi masyarakat baik dari tenaga, uang maupun peralatan. Bentuk partisipasi yang dimaksut, sebagian besar dalam bentuk tenaga yang diperuangkan sesuai dengan HOK setempat (Rp. 75.000,-) dan masyarakat memberikan swadaya berupa tenaga kerja bakti.

\section{Umur dan partisipasi masyarakat pada tahap pelaksanaan}

Berikut ini akan disajikan dalam bentuk

Tabel Umur responden dengan partisipasi masyarakat terhadap PPIP pada tahap perencanaan.

\begin{tabular}{|c|c|c|c|c|c|}
\hline & $\begin{array}{l}\text { Ju } \\
\text { Pa } \\
\text { Pro } \\
\text { Inf }\end{array}$ & $\begin{array}{l}\text { lah } \\
\text { sipasi } \\
\text { ram } \\
\text { struk }\end{array}$ & $\begin{array}{l}\text { Respor } \\
\text { Masya } \\
\text { Ir Perd }\end{array}$ & $\begin{array}{l}\text { en } \\
\text { akat } \\
\text { Pen } \\
\text { aan }\end{array}$ & $\begin{array}{l}\text { menurut } \\
\text { terhadap } \\
\text { angunan }\end{array}$ \\
\hline & & Tal & p Pelaksa & & Total / \\
\hline No & Umur & $\begin{array}{l}\text { Part1 } \\
\text { Aktif }\end{array}$ & $\begin{array}{c}\text { pas1 Mas } \\
\text { Kurang } \\
\text { Aktif }\end{array}$ & $\begin{array}{l}\text { akat } \\
\text { Tidak } \\
\text { Aktif }\end{array}$ & $\begin{array}{c}\text { Persentase } \\
\quad(\%)\end{array}$ \\
\hline 1 & $\leq 40$ & 1 & 1 & 4 & $6 / 40$ \\
\hline 2 & $41-50$ & 1 & 1 & 2 & $4 / 26.7$ \\
\hline 3 & $>50$ & 2 & - & 3 & $5 / 33.3$ \\
\hline & & 4 & 2 & 9 & $15 / 100$ \\
\hline
\end{tabular}

Sumber Data: Diolah dari Data Primer, 2014

Tabel 12 memperlihatkan bahwa responden aktif berjumlah 4 orang, kurang aktif 2 orang sedangkat responden tidak aktif terbanyak dalam tahap pelaksanaan ini dengan jumlag 9 orang. Dimana umur $\leq 40$ tahun yang aktif 1 orang, kurang aktif 1 orang dan jumlah terbanyak 4 orng yang tidak mengambil bagian dalam tahap pelakanaan. Umur 41-50 tahun yang aktif 1 orang, kurang aktif 1 orang dan tidak aktif ada 2 orang. Sedangkan diumur $>50$ tahun dari 5 responden ada 2 orang yang aktif dan 3 orang yang tidak aktif.

\section{Pekerjaan dan partisipasi masyarakat pada tahap pelaksanaan}

Berikut ini Tabel menunjukan bentuk partisipasi reponden terhadap Program Pembangunan Infrastruktur Perdesaan dari pekerjaan pada tahap perencanaan.

Tabel 13. Jumlah responden menurut partisipasi masyarakat terhadap PPIP pada tahap pelaksanaan berdasarkan kategori pekerjaan

\begin{tabular}{|c|c|c|c|c|c|}
\hline \multirow{3}{*}{ No } & \multirow{3}{*}{ Pekerjaan } & \multirow{2}{*}{\multicolumn{3}{|c|}{$\begin{array}{l}\text { Tahap Pelaksanaan } \\
\text { Partisipasi Masyarakat }\end{array}$}} & \multirow{3}{*}{$\begin{array}{c}\text { Total / } \\
\text { Persentase } \\
(\%)\end{array}$} \\
\hline & & & & & \\
\hline & & Aktif & $\begin{array}{c}\text { Kurang } \\
\text { Aktif }\end{array}$ & $\begin{array}{l}\text { Tidak } \\
\text { Aktif }\end{array}$ & \\
\hline 1 & Petani & 4 & 2 & 8 & $14 / 93,3$ \\
\hline
\end{tabular}


Tabel 16. Jumlah Responden menurut Partisipasi Masyarakat Terhadap PPIP Pada Tahap Pemeliharaan

\begin{tabular}{cccc}
\hline No & $\begin{array}{c}\text { Partisipasi } \\
\text { Masyarakat }\end{array}$ & $\begin{array}{c}\text { Jumlah } \\
\text { Responden } \\
\text { (orng) }\end{array}$ & $\begin{array}{c}\text { Presentase } \\
(\%)\end{array}$ \\
\hline \multirow{2}{*}{$\begin{array}{c}\text { Aktif } \\
2\end{array}$} & Kurang Aktif & 8 & 40 \\
3 & Tidak Aktif & 1 & 53.3 \\
& & 6.7 \\
\hline \multicolumn{2}{c}{ Jumlah } & 15 & 100 \\
\hline
\end{tabular}

Sumber Data: Diolah dari Data Primer, 2014

\section{Umur dan partisipasi masyarakat pada tahap pemeliharaan}

Akan disajikan dalam bentuk Tabel Umur responden dengan partisipasi masyarakat terhadap PPIP pada tahap pemeliharaan.

Tabel 17. Jumlah Responden menurut Partisipasi Masyarakat terhadap Program Pembangunan Infrastruktur Perdesaan

\begin{tabular}{cccccc}
\hline & & \multicolumn{3}{c}{ Tahap Pemelihraan } & \multirow{2}{*}{ Total / } \\
\cline { 3 - 5 } No & Umur & \multicolumn{2}{c}{ Partisipasi Masyarakat } & Persentase \\
\cline { 3 - 5 } & & Aktif & $\begin{array}{c}\text { Kurang } \\
\text { Aktif }\end{array}$ & $\begin{array}{c}\text { Tidak } \\
\text { Aktif }\end{array}$ & $(\%)$ \\
\hline 1 & $\leq 40$ & 2 & 3 & 1 & $6 / 40$ \\
2 & $41-50$ & 2 & 2 & - & $4 / 26.7$ \\
3 & $>50$ & 2 & 3 & - & $5 / 33.3$ \\
\hline \multicolumn{2}{c}{ Jumlah } & 6 & 8 & 1 & $15 / 100$ \\
\hline
\end{tabular}

Sumber Data: Diolah dari Data Primer, 2014

Dari Tabel 17 dapat dilihat partisipasi masyarakat terhadap PPIP pada tahap pemelihraan berdasarkan kategori umur. Responden berumur $\leq 40$ tahun yaitu sebanyak 6 orang atau $40 \%$ dari 15 responden yang aktif 2 orang, kurang aktif 3 orang dan tidak aktif ada 1 orang. Responden berumur 41-50 tahun yaitu sebanyak 4 orang atau $26.7 \%$ yang aktif 2 orang dan kurang aktif 2 orang. Sedangkan umur $>50$ tahun yaitu sebanyak 5 orang atau $33.3 \%$ yang aktif ada 2 orang dan sedangkan 3 orang lainnya kurang aktif. Dalam tahap pemelihraan bisa dikatakan sedang dikarenakan jumlah terbanyak ada pada kurang aktifnya responden yang berjumlah 8 orang dan aktif 6 orang sedangkan tidak aktif hanya 1 orang.

\section{Pekerjaan dan partisipasi masyarakat pada tahap pemeliharaan}

Tabel 18 menunjukan bentuk partisipasi reponden terhadap Program Pembangunan Infrastruktur Perdesaan dari pekerjaan pada tahap pemeliharaan.

Tabel 18. Jumlah Responden menurut Partisipasi Masyarakat Terhadap PPIP Pada Tahap Pelaksanaan Berdasarkan Kategori Pekerjaan

\begin{tabular}{|c|c|c|c|c|c|}
\hline \multirow{3}{*}{ No } & \multirow{3}{*}{ Pekerjaan } & \multirow{2}{*}{\multicolumn{3}{|c|}{$\begin{array}{c}\text { Tahap Pemeliharaan } \\
\text { Partisipasi Masyarakat }\end{array}$}} & \multirow{3}{*}{$\begin{array}{c}\text { Total / } \\
\text { Persentase } \\
(\%)\end{array}$} \\
\hline & & & & & \\
\hline & & Aktif & $\begin{array}{c}\text { Kurang } \\
\text { Aktif }\end{array}$ & $\begin{array}{l}\text { Tidak } \\
\text { Aktif }\end{array}$ & \\
\hline 1 & Petani & 6 & 7 & 1 & $14 / 93,3$ \\
\hline 2 & PNS & - & 1 & - & $1 / 6.7$ \\
\hline & Jumlah & 6 & 8 & 1 & $15 / 100$ \\
\hline
\end{tabular}

Sumber Data: Diolah dari Data Primer, 2014

Dari hasil penelitian hampir seluruhnya pekerjaan responden adalah petani yang aktif 6 orang, kurang aktif 7 orang dan tidak aktif ada 1 orang dari 14 orang atau $93.3 \%$. sedangkan 1 responden yang bekerja sebagai PNS kurang aktif dalam tahap pemeliharaan.

\section{Tingkat Pendidikan dan partisipasi} masyarakat pada tahap pemeliharaan

Tabel 19 ini menunjukan parisipasi masyarakat terhadap program pembangunan infrastruktur perdesaan menurut kategori pendidikan dalam tahap perencanaan.

Tabel 19 memperlihatkan tingkat pendidikan SD yang aktif 1 orang, kurang aktif 3 orang dan tidak aktif 1 orang dari jumlah responden 5 orang. Tingkat pendidikan SMP yang aktif 4 orang, kurang aktif 1 orang dari jumlah responden 5 orang. Tingkat pendidikan 
SMA yang aktif 1 orang, kurang aktif 3 orang dari 4 responden. Sedangkan tingkat pendidikan PT yang hanya 1 orang kurang aktif dalam tahap pemeliharaan. Dari tabel ini menunjukan bahwa tingkat partisipasi sedang dikarenakan partisipasi responden kurang aktif dimana ada 8 orang dari 15 responden sedangakn 6 orang lain aktif dalam tahap ini, namun dalam tahap pemeliharaan ini juga masi ada responden yang tidak aktif yaitu 1 orang.

Tabel 19. Pendidikan Responden Dengan Partisipasi Masyarakat Pada Pembangunan Infrastruktur Perdesaan

\begin{tabular}{|c|c|c|c|c|c|}
\hline \multirow{3}{*}{ No } & \multirow{3}{*}{ Pendidikan } & \multirow{2}{*}{\multicolumn{3}{|c|}{$\begin{array}{l}\text { Tahap Pepemeliharaan } \\
\text { Partisipasi Masyarakat }\end{array}$}} & \multirow{3}{*}{$\begin{array}{c}\text { Total / } \\
\text { Persentase } \\
\quad(\%)\end{array}$} \\
\hline & & & & & \\
\hline & & Aktif & Kurang & $\begin{array}{l}\text { Tidak } \\
\text { Aktif }\end{array}$ & \\
\hline 1 & SD & 1 & 3 & 1 & $5 / 33,3$ \\
\hline 2 & SMP & 4 & 1 & - & $5 / 33.3$ \\
\hline 3 & SMA & 1 & 3 & - & $4 / 26.7$ \\
\hline 4 & PT & - & 1 & - & $1 / 6.7$ \\
\hline & Jumlah & 6 & 8 & 1 & $15 / 100$ \\
\hline
\end{tabular}

Sumber Data: Diolah dari Data Primer, 2014

\section{Tingkat Partisipasi Masyarakat Terhadap Program Pembangunan Infrastruktur Perdesaan (PPIP).}

Dari hasil penelitian digunakan tiga kategori untuk mengukur tingkat partisipasi yaitu : partisipasi tinggi, sedang dan rendah. Pengukuran jumlah skor Tingkat partisipasi dapat dilihat pada Lampiran 3, dimana skor tingkat partisipasi masyarakat adalah 85 maka tingkat partisipasi masyarakat Desa Munte berada di kategori sedang. Dimana cara pengukuran tingkat partisipasi dilakukan penjumlah besarnya interval skor untuk menentukan kategori tingkat partisipasi masyarakat secarah menyeluruh didasarkan pada skor kategori tingkat partisipasi individu dikalikan dengan jumlah sampel, dibawa ini adalah penjelasan secara perinci.

Terdapat 3 karakteristik untuk melihat tingkat partisipasi individu masing-masing dapat diberikan skor 1 sampai 3. Sehingga minimum skor $(3 \times 1)$ adalah 3 , maksimim skor yang diperoleh ( $3 \times 3$ ) adalah 9, maka bila jumlah sempel 15, dapat diketahui skor minimum untuk tingkat partisipasi masyarakat $(15 \times 3)$ adalah 45 da skor maksimum ( $15 \times 9)$ adalah 135. Dengan diketahui skor minimum dan maksimum maka diketahui juga jarak interval, yaitu (135-45) / $3=30$, maka tingkat partisipasi rendah berada pada 45-75, sedang 76-106 dan tinggi 107-135.

\section{KESIMPULAN DAN SARAN}

\section{Kesimpulan}

Tingkat partisipasi masyarakat dalam program pembangunan infrastruktur pedesaan (PPIP) yang ada di Desa Munte tergolong dalam tingkat sedang. Pada tahap perencanaan tingkat partisipasi responden sebagian besar tidak aktif, pada tahap pelaksanaan juga partisipasi responden sebagian besar tidak aktif sedangkan pada tahap pemeliharaan partisipasi responden kurang aktif.

\begin{abstract}
Saran
Kurangnya partisipasi masyarakat dalam pembangunan infrastruktur dikarenakan pelaksanaan tidak sesuai dengan hasil rapat sehinga terjadi perselisihan antara masyarakat dan panitia pelaksana, maka dari itu panitia pelaksana harus mengacu dengan hasil rapat dalam melaksanakan program yang ada. Selain itu dalam penelitian ini juga dihasilkan bahwa faktor waktu yang dimiliki oleh masyarakat juga ikut menentukan partisipasinya. Untuk itu mungkin perlu dibuat mekanisme yang berbeda pada tahap kegiatan.
\end{abstract}

\section{DAFTAR PUSTAKA}

Azhari. I. 2011. Tingkat Partisipasi Masyarakat Pada Tahap Perencanaan Dalam Program Neighbourhood Development 
Studi Kasus Desa Jendi Kecamatan Selogiri Kabupaten Wonogiri, Skripsi. Fakultas Teknik Universitas Sebelas Maret Surakarta.

Anonim, 2012.PNPM Mandiri Tujuan Umum dan Tujuan Khusus.http://www.pnpmmandiri.org/index.php.Diambil pada tanggal 26 juni 2014, pukul 01.37pm. , 2013. Pedoman Pelaksanaan Program Pembangunan Infrastruktur Pedesaan Tahun 2013, Direktorat Jendral Cipta Karya Kementrian Pekerjaan Umum.

2013, pdf PNPM Mandiri, Paket Informasi 2012-

Dien. Y. 2012, Partisipasi Masyarakat Terhadap Program Nasional Pemberdayaan Masyarakat Mandiri Perdesaan Didesa Kauditan II Kecamatan Kauditan Kabupaten Minahasa Utara, Sekrpsi, Fakultas Pertanian Unsrat Manado.

Effendi, Bachtiar. 2002. Pembangunan Daerah Otonom Berkeadilan.Yogyakarta: Kurnia Alam Semesta, Uhaindo Media dan Offset

Efraim. H. M. 2010. Partisipasi anggota kelompok tani dalam kegiatan sekolah lapangan pengelolaan tanaman terpadu (SL-PTT) jagung.Skripisi.Fakultas Pertanian Unsrat Manado.

Elmi, S. 2010. Partisipasi Masyarakat Dalam Pembangunan Dan Pengelolahan Prasarana Penyediaan Air Bersih Didesa Wawoosu Dan Didesa Maitewoi, Tesis. Semarang.

Hadin, A. F. 2013, Eksistensi Badan Pengawasan Keuanagn Dan Pembangunan Di Era Otonomi Daerah, Genta. Yogyakarta.

Kartasasmita, Ginanjar. 1996. Memadukan Pertumbuhan dan Pemerataan. Lidesindo, Jakarta.

Kristianto, A. W. 2013, Peningkatan Partisipasi Masyarakat Dalam Pembangunan Infrastruktur Jalan (Studi Kasus Pelaksanaan Program Pembangunan Infrastruktur Pedesaan (PPIP) di Desa
Campurejo Kecamatan Panceng

Kabupaten Gresik).Tesis. Jakarta.

Siagian, Sondang P. 2008. Adminitrasi Pembangunan. Jakarta : PT. Bumi Aksara.

Slamet, 1994, Pembangunan Masyarakat Berwawasan Peran Serta, Surakarta, Sebelas Maret University Press.

Sutami, 2009, Partisipasi Masyarakat Pada Pembangunan Prasarana Lingkungan Melalui Program Pemberdayaan Masyarakat Kelurahan (Ppmk) Di Kelurahan Marunda Jakarta Utara, Tesis, Universitas Diponegoro Semarang.

Undang-Undang Nomor 12 Tahun 2008 Tentang Perubahan Kedua atas UU No. 32 Thn. 2004

Wayan S. 2013. Partisipasi Masyarakat Di Desa Bumi Rapak Kecamatan Kaubun Kabupaten Kutai Timur. eJournal Administrasi Negara.

Yuliaty. M. 2005,Partisipasi Masyarakat Dalam Memelihara Benda Cagar Budaya Di Pulau Penyengat Sebagai Upaya Pelestarian Warisan Budaya Melayu, Tesis, Universitas Diponegoro Semarang

Yulianti. Y. 2012, Analisis Partisipasi Masyarakat Dalam Pelaksanaan Program Nasional Pemberdayaan Masyarakat (PNPM) Mandiri Perkotaan Di Kota Solok, Artikel, Universitas Andalas Padang 